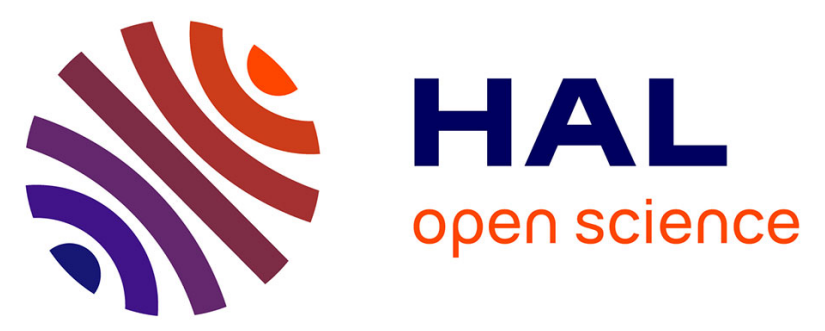

\title{
New insights in cerebral findings associated with fetal myelomeningocele: a retrospective cohort study in a single tertiary centre
}

P Maurice, J Garel, C Garel, F Dhombres, S Friszer, L Guilbaud, E Maisonneuve, H Ducou Le Pointe, E Blondiaux, J-M Jouannic

\section{To cite this version:}

P Maurice, J Garel, C Garel, F Dhombres, S Friszer, et al.. New insights in cerebral findings associated with fetal myelomeningocele: a retrospective cohort study in a single tertiary centre. BJOG: An International Journal of Obstetrics and Gynaecology, 2021, 128 (2), pp.376-383. 10.1111/14710528.16185 . hal-03263489

\section{HAL Id: hal-03263489 \\ https://hal.sorbonne-universite.fr/hal-03263489}

Submitted on 17 Jun 2021

HAL is a multi-disciplinary open access archive for the deposit and dissemination of scientific research documents, whether they are published or not. The documents may come from teaching and research institutions in France or abroad, or from public or private research centers.
L'archive ouverte pluridisciplinaire HAL, est destinée au dépôt et à la diffusion de documents scientifiques de niveau recherche, publiés ou non, émanant des établissements d'enseignement et de recherche français ou étrangers, des laboratoires publics ou privés. 
1 New insights in cerebral findings associated with fetal myelomeningocele: a

2 retrospective cohort study in a single tertiary centre

4 Maurice $\mathrm{P}^{1,2}$, Garel $\mathrm{J}^{3}$, Garel $\mathrm{C}^{3}$, Dhombres $\mathrm{F}^{1,2}$, Friszer $\mathrm{S}^{1,2}$, Guilbaud $\mathbf{L}^{1,2}$,

5 Maisonneuve $\mathrm{E}^{1,2}$, Ducou Le Pointe $\mathrm{H}^{3}$, Blondiaux $\mathrm{E}^{3}$, Jouannic $\mathrm{JM}^{1,2}$

6 'Service de Médecine Foetale, Centre de Référence Maladie Rares MAVEM, Hôpital

7 Armand Trousseau, Médecine Sorbonne Université, APHP, Paris, France

8 2Refrence Center for Rare Disease: vertebral and spinal cord anomalies,

9 Trousseau, France

10 3Service de Radiopédiatrie, Hôpital Armand Trousseau, Médecine Sorbonne Université,

11 APHP, Paris, France

12 Corresponding author: Jean-Marie Jouannic, Service de Médecine Foetale, Hôpital

13 Armand Trousseau, 26 avenue Arnold Netter, 75012 Paris, France

14 Tel : +33171735228

15 Email: jean-marie.jouannic@aphp.fr

17 Shortened running Tittle: fetal cerebral anomalies associated with MMC 


\section{Abstract}

23 Objective: to investigate cerebral anomalies other than Chiari type 2 malformation

24 in fetuses with myelomeningocele.

25 Design: A retrospective cohort study in a single tertiary centre.

26 Setting: a review of associated cerebral anomalies in cases with prenatal diagnosis of

27 myelomeningocele.

28 Population: 70 cases of foetal myelomeningocele.

29 Methods: Ultrasound and MRI images were blindly reviewed. Postnatal imaging and

30 results of the post-mortem results were also reviewed. The association between

31 cerebral anomalies and the following US findings was measured: level of the

32 defect, ventriculomegaly, microcephaly and foetal talipes.

33 Main outcome measures: A microcephaly was observed in $32 / 70$ cases $(46 \%)$, a 34 ventriculomegaly was observed in $39 / 70$ cases (56\%). Other cerebral anomalies 35 were diagnosed in $47 / 70(67 \%)$.

36 Results : Other cerebral anomalies were represented by $42 / 70$ cases with 37 abnormal CC (60\%), 8/70 cases with PNH (11\%), 2/70 cases with abnormal gyration 38 (3\%). MRI only performed in foetal surgery cases confirmed US findings in all 39 cases, and provided additional findings in 2 cases (PNH). Risk ratios of foetal

40 cerebral anomalies associated with MMC did not reach significance for 41 microcephaly, ventriculomegaly, talipes and for the level of the defect There was 42 an overall good correlation between pre and postnatal findings with a Kappa value of $430.79[0.57-1]]_{195 \%}$ and a proportion of agreement of $82 \%$.

44 Conclusion: foetal brain anomalies other than Chiari type 2 malformation, are 45 frequently observed in foetuses with myelomeningocele, predominantly 
46 represented by CC anomalies. Whether these associated cerebral anomalies

47 should have an impact on selecting cases eligible for fetal surgery needs further

48 evaluation.

49 Funding statement: This study was funded by a grant from the Programme

50 Hospitalier de Recherche Clinique - PHRC 2013 (French Ministry of Health) and

51 was promoted by La Délégation à la Recherche Clinique et I'Innovation de I'AP -

52 HP (Assistance Publique-Hôpitaux de Paris).

54 Key-words: myelomeningocele, prenatal diagnosis, ultrasound, cerebral anomalies, 55 corpus callosum

57 Tweetable abstract: foetal cerebral anomalies other than Chiari type 2 malformation, 58 microcephaly and ventriculomegaly may be associated with MMC in up to $67 \%$ of the 59 cases.

60 
Myelomeningocele (MMC) represents a specific form of neural tube defect with

63 an incidence of approximatively 3-4 per $\mathbf{1 0 . 0 0 0}$ live births in Europe ${ }^{1}$. The exposure of

64 the non-neurulated spinal cord and nerve roots to external environment is

65 responsible for motor dysfunction (weakness or paralysis) and for both bowel and

66 bladder dysfunction ${ }^{2}$. In addition, there are specific brain anomalies associated with

67 this defect, most commonly Chiari type 2 malformation and frequent associated ventriculomegaly and microcephaly ${ }^{3}$.

In neonates undergoing surgical repair of myelomeningocele, a wide spectrum in

70 terms of size, shape, level of defect and appearance of cerebral structures is observed

71 (the posterior fossa structures, the corpus callosum and the cerebral cortex) $)^{3,4}$. Chiari

72 type 2 malformation is observed in almost all cases of $\mathrm{MMC}^{4,5}$. Hydrocephalus is

73 frequently seen, being present in about half of the patients with MMC $^{3}$. Corpus

74 callosum (CC) anomalies are also frequent in cohorts of adult patients, with

75 controversies on the underlying mechanism leading to these anomalies, as they are

76 often associated with hydrocephalus in these patients ${ }^{3,6,7}$.

77 There is no available data on the incidence of corpus callosum and cortex 78 abnormalities in foetuses with MMC. In the setting of foetal surgery, these data are of 79 utmost importance since prenatal repair is theoretically reserved for foetuses 80 presenting with MMC with no other anomaly than Chiari type 2 malformation, 81 ventriculomegaly, microcephaly or talipes.

82 We aimed to retrospectively review all cases of MMC referred to our centre and

83 for which complete ultrasound examinations of the foetal brain performed by an 
84 experienced sonographer were reviewed by two independent operators blinded to the

85 perinatal outcome.

87 Material and Methods

This was a retrospective study of 70 cases of fetuses with MMC examined between November 2013 and February 2019 in the setting of the PRIUM study8: French

90 study on prenatal repair of foetal myelomeningoceles using open surgery technique ${ }^{9}$

91 (Clinical Trial registration NCT01983345; Institutional Review Board approval 13048).

92 There was no patient and public involvement. Patients with suspicion of foetal MMC

93 were referred to our centre. As part of our usual plan of care, all cases are evaluated

94 by a second line US examination performed by one experienced operator (CG).

95 Additional MRI examination is offered either systematically in case of foetal 96 surgery, or when additional anomalies are suspected at ultrasound examination.

97 In our centre there is no policy of systematic fetal MRI in case of typical MMC at 98 second line US examination.

The second line ultrasound (US) was performed by an experienced operator 100 using a Aplio 400 unit (Canon Medical Systems, Otawara, Japan) with vector and 101 curved-array transducers and magnified images focused on the spine and spinal cord 102 utilizing high frequency $(8-15 \mathrm{MHz})$ linear array transducers. When abdominal route was 103 not sufficient for detailed examination of the foetal brain, and depending on the foetal 104 position, a vaginal examination was performed using high frequency vaginal probes. An 105 entire examination of the foetal brain, including examination of the $\mathrm{CC}$ was performed.

106 The fetal MRI examinations were performed using a 1.5 Tesla Unit (Achieva; 
107 Philips Medical Systems, Best, The Netherlands from 2013 to 2015 and Optima

108 MR450w; General Electric (GE), Waukesha, WI since 2016). SSFSE sequences

109 were acquired for all foetuses in three orthogonal spaces. In order to reduce

110 motion artefacts, maternal sedation was systematically offered. 2D images in the

111 three planes of the space were repeated until the quality was deemed good.

112 The gestational age at diagnosis of MMC was recorded. When several US scans

113 were performed, results of the first complete evaluation, the nearest to the diagnosis,

114 were taken into account. The level of the MMC defect was classified as low when

115 the uppermost vertebral defect was below L3 or as high when it was L3 or higher.

116 Regarding the fetal brain, the US parameters recorded were (1) microcephaly

117 defined by head circumference $<3^{\text {rd }}$ centile $^{10}$, (2) presence or absence of

118 ventriculomegaly defined by a diameter of the ventricular atrium measured on the

119 axial view $\geq \mathbf{1 0} \mathrm{mm}$, (3) anomalies of the CC and (4) associated parenchymal

120 anomalies represented by subependymal heterotopia or gyration disorders.

121 Anomalies of the CC included absent, short, thick or apparently normal but stretched

122 CC. The CC was defined as short when length measurement was $<3^{\text {rd }}$ centile

123 using reference curves by Cignini et al. ${ }^{11}$. A short CC was then classified as

124 complete (figure 1) or incomplete (figure 2); when incomplete, the missing part

125 was noted (rostrum, genu, body, splenium). A CC was defined as thick when $\geq 3$

$126 \mathrm{~mm}$ at the mid-coronal plane as described by Achiron et al. ${ }^{12}$. Extra-cranial

127 anomalies and the presence of foetal talipes were also recorded. 
130 the benefice-risk balance of prenatal versus postnatal repair. Foetal karyotype

131 analysis was offered in all cases. According to the French law, termination of 132 pregnancy (TOP) was possible at parental request irrespectively of gestational age.

133 All cases of confirmed diagnosis of MMC were included. Cases associated with 134 chromosomal anomalies or polymalformative syndromes were excluded. We also 135 excluded cases for which termination of pregnancy (TOP) was performed before 20 136 weeks of gestational age (GA) since corpus callosum anatomy could not be evaluated. Results of the post-mortem (PM) examination were recorded when accepted by 138 the parents in cases of TOP. The PM examination protocol included a two-month 139 period of formalin fixation of the foetal brain to allow anatomical examination of 140 the foetal brain structures. As part of our usual plan of care in liveborn neonates, 141 transfontanellar US examination is systematically performed during the first week 142 of life and cerebral MRI examination is systematically performed during the first 3 143 months of life regardless of the timing of the surgery.

144 Both prenatal and postnatal imaging (head US and/or brain MRI) were reviewed 145 blind to the perinatal outcome by the same team (PM and JG). Cerebral anomalies were 146 analysed as described above. For the CC postnatal imaging, the following features 147 were recorded: (1) length of the corpus callosum, considered as short when 148 inferior to the $3^{\text {rd }}$ centile according to $\mathrm{C}$. Garel curve ${ }^{13}(2)$ objective thickness of the 149 corpus callosum measured at the level of the genu, body, and splenium, and considered 150 thickened when one of the measurement was superior to the $97^{\text {th }}$ percentile ${ }^{13}$.

152 Statistical analysis. 
154 Statistical Computing, Vienna, Austria) and STATA, version 15 (StataCorp, College

155 Station, Texas, USA). The association between cerebral anomalies and the

156 following US findings was measured by computing Risk Ratios (RR) and 95\%

157 confidence intervals: level of the defect, ventriculomegaly, microcephaly and

158 foetal talipes. The relationship between decision of TOP and cerebral anomalies was

159 tested by Odds Ratio (OR), and a $\mathrm{P}$ value $<0.05$ was considered statistically significant.

160 Adjusted kappa coefficients (Cohen weighted kappa) for CC categories (normal,

161 stretched, short and absent) were computed to test for the agreement between prenatal

162 and postnatal findings. Adjusted kappa values $<0.6$, between 0.6 and 0.8 , and $>0.8$ were

163 considered to represent poor, moderate, and good agreement, respectively.

165 Results

166 During the study period, 109 pregnant women with suspicion of foetal MMC were

167 referred to our centre (figure 3). The diagnosis was revised in 26 cases including limited

168 dorsal myeloschisis $(\operatorname{LDM})^{14}(n=9)$ or borderline types of LDM-MMC $(n=14)$, the latter

169 being characterized by the association between a saccular dysraphism with a thick

170 membrane coverage, a spinal cord stretched to the sac wall by a fibrous stalk, the

171 absence of nerve roots within the sac and either a Chiari type 2 malformation or a

172 reduced cisterna magna. Moreover, other types of dysraphisms were observed,

173 including lipomyelomeningocele $(n=1)$, complex dysraphism $(n=1)$ and meningocele

$174(n=1)$. The diagnosis of MMC was confirmed in 83 cases. Thirteen cases were excluded:

175 polymalformative syndromes $(n=6)$, MMC with associated diastematomyelia $(n=3)$, TOP 
176 before 20 weeks of gestation $(n=2)$ and cases for which satisfying study of the corpus

177 callosum was not available due to foetal position $(n=2)$. In these latter two cases, MRI

178 was not performed since the parents opted for TOP and declined the PM 179 examination. The remaining 70 cases of $\mathrm{MMC}$ were included. Fetal karyotype 180 analysis was performed in $39 / 70$ cases and revealed no chromosomal anomalies.

182 Prenatal imaging findings

183 The median GA at second line US examination was 23 weeks $^{+3 d}$ (range: 20 184 weeks $^{+3 d}-25$ weeks $\left.^{+6 d}\right)$. The uppermost vertebral defect was below L3 in 45/70 185 cases (64\%). Foetal talipes was associated with MMC in $20 / 70$ cases $(29 \%)$. A 186 Chiari type 2 malformation was observed in all cases. A microcephaly was 187 observed in $32 / 70$ cases (46\%), a ventriculomegaly was observed in $39 / 70$ cases 188 (56\%). Overall, other cerebral anomalies were diagnosed in $47 / 70(67 \%)$ of the 189 cases in the prenatal period. We observed $42 / 70$ cases with abnormal CC $(60 \%)$, 190 8/70 cases with PNH (11\%), 2/70 cases with abnormal gyration (3\%). Additional

191 fetal MRI was performed in $12 / 70$ cases (17\%) only in cases where foetal surgery 192 was considered. MRI confirmed US findings in all cases, and provided additional 193 findings in 2 cases (PNH). 
197 anomalies were observed in $10 / 39$ cases (26\%) (figure 3 ). In all these cases,

198 patients opted for TOP and when performed, no additional findings were identified

199 on PM examination. In the remaining 29 cases, the parents opted for prenatal

200 repair in 6 cases, for conventional postnatal repair in 6, and for TOP in 17 cases.

201 The CC was considered as abnormal in $26 / 39$ cases $(67 \%)$. The CC was

202 stretched in 5 cases, associated with ventriculomegaly $\geq 13 \mathrm{~mm}$ in all these cases.

203 The CC was considered short and complete in 10 cases, and short but incomplete

204 in 10 other cases. When the CC was short, it was thickened in 11/20 cases. There

205 was a complete CC agenesis in one case.

206 PNH were diagnosed by prenatal imaging in 6/39 cases (15\%). In four cases,

207 they were detected at the second line of ultrasound examination. In addition, in

208 two other cases, PNH were detected at systematic MRI examination performed as

209 part of the management of prenatal surgery cases.

210 Abnormal gyration pattern was observed in $2 / 39$ cases $(5 \%)$ at the second

211 line ultrasound examination only. In one case, the CC was normal and in the other

212 case, the CC was short but complete. In these 2 cases, MRI was not performed

213 and PM was declined.

214 MMC without ventriculomegaly

215 In cases not associated with ventriculomegaly, no additional cerebral

216 anomalies were observed in $13 / 31$ cases (42\%) (figure 3 ). Among these cases,

217 parents opted for prenatal repair in 3 cases, for conventional postnatal repair in 4 
cases, and for TOP in 6 cases.

The CC was considered as abnormal in $16 / 31$ cases (52\%). The CC was

220 considered short and complete in 14 cases, and short but incomplete in 2 other

221 cases. When the CC was short, it was thickened in 2/16 cases.

PNH were diagnosed by prenatal imaging in 2/31 cases (6\%). In one case,

223 PNH was detected at the second line of ultrasound examination and confirmed by

224 MRI. In the other case, PNH was detected at the systematic MRI examination. No 225 case of abnormal gyration pattern was observed.

227 Perinatal outcome

Overall, there were 25/70 liveborn neonates including $13(52 \%)$ cases that underwent a prenatal repair performed at a median age of $24^{+5 d}$ weeks (range: 21

230 weeks $^{+3 d}-25$ weeks $^{+6 d}$ ) (figure 4). One neonatal death occurred in one case at day 9

231 (postnatal repair group). Ventriculo-peritoneal shunt was indicated in 3 and 6 232 children in the prenatal repair and postnatal repair groups, respectively. The 24

233 live children are currently 6 to $\mathbf{4 0}$ months old with normal neurobehavioral

234 development, including the 10 and the 5 cases with either PNH or CC anomalies in

235 the prenatal surgery group and postnatal repair group, respectively.

A TOP was elected by the parents in 45 cases and a PM examination was 237 performed in 39 cases. Detection of associated CNS anomalies (CC anomalies, 238 PNH or abnormal gyration) was not significantly associated with a decision of 
239 TOP $(O R=1.2, p=0.06)$. Risk ratios of foetal cerebral anomalies associated with

240 MMC did not reach significance for microcephaly, ventriculomegaly, talipes and

241 for the level of the defect (Figure S1).

243 Correlation between prenatal imaging and postnatal or post-mortem findings

244 A complete review of the prenatal and postnatal imaging was possible in 18/25

245 live born neonates. Among the cases with a complete CC assessed prenatally, there

246 were 2 cases with complete but stretched CC associated with a postnatal

247 ventriculomegaly. There was an overall good correlation between pre and postnatal

248 findings with a Kappa value of $0.79[0.57-1] c 195 \%$ and a proportion of agreement of $82 \%$.

251 Discussion

252 Main findings

253 Foetal cerebral anomalies in case of MMC have been widely described and

254 comprise Chiari II malformation, ventriculomegaly and microcephaly. Our study

255 suggests that other cerebral anomalies may be present in up to $67 \%$ of the cases.

256 CC anomalies were the most frequent (60\%). Other anomalies included heterotopia or 257 suspicion of gyration disorders.

258

259 Strengths and limitations 
261 by an experienced sonographer in foetal brain imaging with an independent review

262 performed by two observers blinded to the perinatal outcome using a standardized grid.

263 In addition, we were able to demonstrate a good correlation between prenatal and 264 postnatal imaging. However, considering the retrospective design of our study, 265 correlation between prenatal imaging findings and PM examination was possible in only $26640 \%$ of the cases in which the parents opted for TOP. Moreover, we observed some 267 discrepancies between prenatal imaging and PM examination in up to $50 \%$ of the cases.

268 This was in part the consequence of an absence of standardised grid and curves for 269 examination of the $\mathrm{CC}$ at $\mathrm{PM}$ examination. In line with this, we observed that $\mathrm{CC}$ 270 considered with abnormal length at prenatal imaging were classified as normal at PM 271 examination.

273 Interpretations

274 Some structural anomalies are virtually unique to patients with MMC and are

275 mainly represented by a complex pattern of cerebral dysplasia known as Chiari II 276 malformation, ventriculomegaly and microcephaly ${ }^{3,4,15}$. Other cerebral anomalies, 277 not specific to MMC, have been reported in cohorts of children and adults ${ }^{4}$. Among 278 these lesions, CC anomalies are present in up to 70 to $90 \%$ of postnatal cases ${ }^{16-19}$.

279 The most frequent CC anomalies comprise mainly CC hypoplasia, usually partial 280 hypoplasia of the genu and body, but also CC partial agenesis (mostly rostrum 281 agenesis) ${ }^{6,16}$. Complete CC agenesis remains extremely rare in this population ${ }^{6,16}$. The 282 underlying pathological mechanism of these CC anomalies remains debatable. In case 283 of postnatal hydrocephalus, the CC often appears as stretched and thin and is 
considered as a usual finding ${ }^{3}$. Similarly, significant ventriculomegaly could be

285 the underlying mechanism of the stretched CC feature we observed in 5 foetuses

286 in our series. In the prenatal period, the high prevalence of early ventriculomegaly

287 in case of MMC also raises the question of its impact on CC development, which

288 is critical between 19 and 21 weeks, with significant growth of the splenium until

28924 weeks ${ }^{12,20}$. Interestingly, our rate of CC anomalies of $60 \%$ appears to be lower than

290 reported in children or adults patients ${ }^{6,16-18}$. We also described a novel feature of

291 short CC $<3^{\text {rd }}$ centile, a majority of them $<1^{\text {st }}$ centile $(60 \%$ of cases $)$, whether

292 complete or incomplete and, in some cases, associated to a thickened feature.

293 These CC anomalies were observed in cases, either with normal ventricular

294 measurement or with moderate ventriculomegaly at midgestation. This casts

295 doubt on a possible causal relationship between ventriculomegaly and CC

296 anomalies and is a clue pointing to the existence of a spectrum of abnormalities

297 of brain development in foetuses with MMC. Also, we would like to highlight the

298 fact that in our experience (unpublished data), it is not possible to thoroughly

299 discriminate a short but complete CC and a CC with very partial agenesis using

300 current foetal imaging techniques. Thus, some CC considered short but complete

301 in this study might be erroneously classified. Overall, the existence of these

302 additional callosal anomalies raises the question of their impact on the postnatal

303 development of these children and requires further evaluation. Indeed, even in

304 normal foetuses, the prognosis of short or thick CC remains a matter of debate

305 considering the very few data available ${ }^{21-23}$.

306 Besides these already known CC anomalies associated with MMC, we also found

$307 \mathrm{PNH}$ and cortical anomalies in $11 \%$ and $3 \%$ of the cases respectively. Interestingly, in 
308 one of the two prenatal cases in which abnormal Sylvian appearance was suspected,

309 gyration was considered as normal at postnatal imaging. Excessive thinness of the

310 pericerebral space in foetuses with MMC makes it difficult to properly analyse the

311 sylvian fissure and it probably accounts for one case being inappropriately classified as

312 gyration abnormalities at the beginning of the study. The impact of these cortical

313 associated malformations on the postnatal neurobehavioral development also requires

314 further assessment.

315 The timing of the prenatal diagnosis of these associated cerebral anomalies

316 requires specific attention, especially within the context of fetal surgery for MMC. The

317 majority of the centres offering prenatal repair for $\mathrm{MMC}$, whatever the technique used

318 (open v. fetoscopic surgery), do comply with the MoM study criteria. Thus, only cases of

319 isolated MMC are eligible to a prenatal repair ${ }^{9}$. The common associated findings, such

320 as talipes, do not preclude prenatal surgery ${ }^{9}$. In our centre, 10/13 cases with foetal

321 surgery were found to be associated with cerebral anomalies suspected in the

322 prenatal period and represented by short CC in 7 cases and/or PNH in 6 cases. In

323 the first five cases, these anomalies were suspected between 28 to 32 weeks after

324 foetal surgery had been performed. All these children, although still young, 24

325 months to four years old at the moment, display normal development. In the other

326 five cases, either short appearance of the CC or suspicion of PNH were suspected

327 before foetal surgery. The parents were informed of these findings and maintained

328 their request for a prenatal repair. Considering the high rate of $\mathrm{CC}$ anomalies in the

329 postnatal series and the favourable outcome of isolated PNH in non-MMC foetuses ${ }^{24,25}$,

330 we did not consider these findings as a contraindication for a prenatal repair. However,

331 these children will require specific neurobehavioral development follow-up in the future. 


\section{Conclusion}

335 We conclude that foetal brain anomalies other than Chiari II malformation,

336 ventriculomegaly and microcephaly are frequently observed during the prenatal

337 period in foetuses with MMC and are predominantly represented by CC anomalies.

338 Whether these associated cerebral anomalies should have an impact on selecting 339 cases eligible to a foetal surgery needs further evaluation.

342 Disclosure of interest:

343 Non declared. Completed disclosure of interest forms are available to view online as 344 supporting information.

346 Contribution to authorship:

347 JMJ, CG and PM contributed to the conception and design of the study and to drafting 348 the work. PM and JG reviewed all prenatal and postnatal imaging. LG, EM, SF, FD, HDL 349 and EB provided the statistical analysis and interpretation of data, and revised it critically

350 for important intellectual content. All authors read and approved the final manuscript.

352 Details of ethical approval:

353 Clinical Trial registration NCT01983345; Institutional Review Board approval 13048

354 Comité de Protection des Personnes Ile de France XI, 04 ${ }^{\text {th }}$ July 2013. 
Funding statement:

357 This study was funded by a grant from the Programme Hospitalier de Recherche

358 Clinique - PHRC 2013 (French Ministry of Health) and was promoted by La Délégation

359 à la Recherche Clinique et I'Innovation de l'AP-HP (Assistance Publique Hôpitaux de 360 Paris).

\section{References}

364 1- Khoshnood B, Loane M, de Walle H, Arriola L, Addor MC, Barisic I et al. Long term 365 trends in prevalence of neural tube defects in Europe: population based study. 366 BMJ. 2015; 351: h5949.

367 2- Adzick NS. Fetal surgery for spina bifida: past, present, future. Semin Pediatr Surg $368 \quad 2013 ; 22: 10-17$.

369 3- Juranek J. Anomalous development of brain structure and function in spina bifida 370 myelomeningocele. Dev Disabil Res Rev 2010;16:23-30.

371 4- Januschek E, Röhrig A, Kunze S, Fremerey C, Wiebe B, Messing-Jüunger M.

372 Myelomeningocele - a single institute analysis of the years 2007 to 2015 . Childs

373 Nerv Syst 2016; 32: 1281-1287.

374 5- Beuriat PA, Szathmari A, Rousselle C, Sabatier I, Di Rocco F, Mottolese C. Complete

375 reversibility of the Chiari type II malformation after postnatal repair of

376 myelomeningocele. World Neurosurg 2017; 108: 62-68.

377 6- Hannay HJ, Dennis M, Kramer L, Blaser S, Fletcher JM. Partial agenesis of the 378 corpus callosum in spina bifida meningomyelocele and potential compensatory 379 mechanisms. J. Clin. Exp. Neuropsychol 2009;31:180-194. 
7- Barkovich, J. Pediatric neuroimaging. Philadelphia, PA: Lippincott, Williams \&

381 Wilkens; 2005.

8- Friszer S, Dhombres F, Di Rocco F, Rigouzzo A, Garel C, Guilbaud L et al.

383 Preliminary results from the French study on prenatal repair for fetal myelomeningoceles

384 (the PRIUM study). J Gynecol Obstet Biol Reprod. 2016 Sep;45(7):738-44.

385 9- Adzick NS, Thom EA, Spong CY, Brock JW 3rd, Burrows PK, Johnson MP, et al.;

386 MOMS Investigators. A randomized trial of prenatal versus postnatalrepair of

387 myelomeningocele. N Engl J Med 2011;364: 993-1004.

10- Salomon LJ, Duyme M, Crequat J, Brodaty G, Talmant C, Fries N et al.

389 French fetal biometry: reference equations and comparison with other charts.

390 Ultrasound Obstet Gynecol. 2006 Aug;28(2):193-8.

391 11- Cignini P, Padula F, Giorlandino M, Brutti P, Alfo M, Giannarelli D et al. Reference

392 charts for fetal coprus callosum length. J Ultrasound Med 2014;33:1065-1078.

393 12- Achiron R and Achiron A. Development of the human fetal corpus callosum: a hight-

394 resolution, cross-sectional sonographic study. Ultrasound Obstet Gynecol 2001;18:343395347.

396 13- Garel C, Cont I, Alberti C, Josserand E, Moutard ML, Ducou le Pointe H. Biometry of

397 the corpus callosum in children: MR imaging reference data. AJNR Am J Neuroradiol.

3982011 Sep;32(8):1436-43.

399 14- Friszer S, Dhombres F, Morel B, Zerah M, Jouannic JM, Garel C. Limited Dorsal

400 Myeloschisis: A Diagnostic Pitfall in the Prenatal Ultrasound of Fetal Dysraphism. Fetal

401 Diagn Ther. 2017;41(2):136-144. 
402 15- McLone DG, Knepper PA. The cause of Chiari II malformation: a unified theory.

403 Pediatr Neurosci. 1989; 15:1-12.

404 16- Miller E, Widjaja E, Blaser S, Dennis M, Raybaud C. The old and the new:

405 supratentorial MR findings in Chiari II malformation. Childs Nerv. Syst. 2008;245:563$406 \quad 575$, May 2008.

407 17- Elgamal EA, Elwatidy SM, Alhabib AF, Jamjoom ZB, Murshid WR, Hassan HH et al.

408 Agenesis of the corpus callosum associated with spinal open neural tube defect. Saudi

409 Med J. 2014 Dec;35 Suppl 1:S57-63.

410 18- Herweh C, Akbar M, Wengenroth M, Blatow M, Mair-Walther J, Rehbein N et al.

411 DTI of commissural fibers in patients with Chiari II-malformation. Neuroimage. 2009 Jan $412 \quad 15 ; 44(2): 306-11$.

413 19- Crawley JT, Hasan K, Hannay HJ, Dennis M, Jockell C, Fletcher JM. Structure, 414 integrity, and function of the hypoplastic corpus callosum in spina bifida 415 myelomeningocele. Brain Connect. 2014 Oct;4(8):608-18.

416 20-Malinger $\mathrm{G}$ and Zakut. The corpus callosum: normal fetal development as shown by 417 transvaginal sonography. AJR Am. J. Roentgenol. 1993;161:1041-1043.

418 21- Meidan R, Bar-Yosef O, Ashkenazi I, Yahal O, Berkenstadt M, Hoffman C et al.

419 Neurodevelopmental outcome following prenatal diagnosis of a short corpus

420 callosum. Prenat Diagn. 2019 May;39(6):477-483.

421 22- Lerman-Sagie T, Ben-Sira L, Achiron R, Schreiber L, Hermann G, Lev D et al. 422 Thick fetal corpus callosum: an ominous sign? Ultrasound Obstet Gynecol. 2009 423 Jul;34(1):55-61. 
424 23- Shinar S, Har-Toov J, Lerman-Sagie T, Malinger G. Thick corpus callosum in 425 the second trimester can be transient and is of uncertain significance. Ultrasound 426 Obstet Gynecol. 2016;48:452-457.

427 24- Deloison B, Sonigo P, Millischer-Bellaiche AE, Quibel T, Cavallin M, Benoist G et al.

428 Prenatally diagnosed periventricular nodular heterotopia: Further delineation of the 429 imaging phenotype and outcome. Eur J Med Genet. 2018 Dec;61(12):773-782.

430 25- Blondiaux E, Sileo C, Nahama-Allouche C, Moutard ML, Gelot A, Jouannic JM 431 et al. Perinodular heterotopia on prenatal ultrasound and magnetic resonance 432 imaging. Ultrasound Obstet Gynecol. 2013 Aug;42(2):149-55.

433

434

435 
436 Legend to the figures:

437 Figure 1: Ultrasound midsagittal view of the brain in a foetus at $\mathbf{2 5}$ weeks with 438 myelomeningocele (uppermost vertebral defect level L3). Short (length $<3^{\text {rd }}$ 439 centile) but complete corpus callosum (arrows).

441 Figure 2: Foetus at 24 weeks with myelomeningocele (uppermost vertebral defect

442 level L3). Short (length $<1^{\text {st }}$ centile) thickened and incomplete corpus callosum 443 (arrows) with suspicion of rostrum and splenium agenesis. Midsagittal view of 444 the brain: A ultrasound image, and B : T2 weighted MRI image.

446 Figure 3: Flow chart of the dysraphism cases. MMC: myelomeningocele; LDM: limited 447 dorsal myeloschisis; TOP: termination of pregnancy; CC: corpus callosum; $\mathrm{PNH}$ : 448 perinodular heterotopia.

450 Figure 4: Flow chart of the perinatal outcome of the $\mathbf{7 0}$ myelomeningocele cases.

451 MMC: myelomeningocele; CC: corpus callosum; $\mathrm{PNH}$ : perinodular heterotopia. 452

453 Figure S1: Risk ratio of foetal cerebral anomalies other than Chari type 2 454 malformation in the $\mathbf{7 0}$ myelomeningocele cases. HC: head circumference. 